\title{
Theorectical Reflections on the Teaching of Literacy in Zambian Bantu Languages
}

\author{
Joseph M. Mwansa
}

\author{
*Corresponding Author: Joseph M. Mwansa
}

\begin{abstract}
In this paper I reflect on the theoretical aspects of teaching literacy in Zambian Bantu languages which have been largely influenced by research in English. I argue that it is important to consider language specific factors such as the phonological and morphological features that influenced the design of orthographies in Zambian languages and English and also the social-economic and cultural contexts in which reading instruction is conducted.
\end{abstract}

The paper also critiques, in the light of the above, the literacy programmes which have been used in Zambia in teaching initial literacy in relation to the scientific literature available. It will highlight gaps which require research in our understanding of how reading and literacy instruction should be conducted to build more effective home-grown techniques of literacy instruction.

Keywords: Literacy education, language teaching, Zambian Bantu languages, initial literacy

\section{INTRODUCTION}

Reading research in English has been very influential in the field of reading on theoretical models of reading as well as reading methodology. However, in recent years many voices have been raised against relying on findings in a language which has an atypical orthography as we discuss below (see Share, 2008, for a detailed review). It is, therefore, argued that language specific properties such as the phonological and morphological features that influence orthographies need to be considered. Furthermore, the social-cultural and economic contexts in which teaching of learning is taking place also need to be taken into consideration. In Zambia, the colonial legacy of English is all pervasive in the education system. In particular, the teaching of Zambian Bantu languages has been largely influenced by methods from English and the syllabi reflect features that one would normally associate with English second language methodology. The low status of local languages has meant that few students venture into specialising in African languages at university level, thus creating a shortage of experts who might counter the insidious effects of English on the teaching of local languages.

In this paper, I present reflections on the teaching of Zambian languages by first reviewing differences in the phonological and morphological features that have influenced the orthographies of Zambian languages and English. Secondly, I consider the implications these in relation to the skills that have been identified as prerequisites for effective reading instruction: phonological awareness, phonics, oral reading fluency, vocabulary and comprehension. In addition, I also comment of the social and economic context in which most of our children learn. In the course of discussing these issues, I highlight areas that need further research that should enable us to have a better understanding of what is involved in learning to read in Zambian Bantu languages and how we can improve instruction. I also critique some of the recent literacy programmes implemented in Zambia.

\section{THE LiNGUISTIC BACKGROUND}

Most of the world's writing systems are based on the spoken language below the word such as syllables and phonemes even the so-called logographic writing system of the Chinese is actually morpho-syllabic in that it combines morphemes with syllables and so it is not entirely meaning-based. Zambian languages use the alphabetic writing system and the Roman (or Latin) script although a syllabary (syllable based) could also have worked as I point out below. Alphabetic writing systems are based on what is called the alphabetic principle which is the understanding that phonemes (sounds) should have a one-to- one correspondence with graphemes (letters). This is the ideal which in most 
cases is not perfectly met and hence we have shallow and deep orthographies. Orthographies which have a clearer relationship between letters and sounds are said to be shallow or transparent while those where this relationship is not clear are deep or opaque. English is an example of the latter while Zambian Bantu languages have shallow orthographies. In this paper, the Zambian languages referred to are those used in the education system which are: Bemba, Kikaonde, Lozi, Lunda, Luvale, Nyanja and Tonga. The total number of Bantu dialects in Zambia is put at 72 which cluster into some 15-20 independent languages.

When a child learns to read, what she learns essentially is how graphemes map onto her spoken language. This is made easier if the orthography is shallow and the child is learning a mother tongue or familiar language because this facilitates comprehension of what is being decoded. It also follows from this that transfer of reading skills will be easier from a shallow orthography to an opaque one. In the case of Zambia, this means transitioning from a Zambian Bantu language to English. In this section I review the phonological and morphological features of Zambian Bantu languages and how they are reflected in the orthographies and compare them to English to show why we should be wary of basing our instructional methods on research in reading in English.

\section{Phonology}

\subsection{Vowels}

Although there are Bantu languages that have up to 9 vowels such as Bila in the Democratic Republic of Congo (Kutsch-Lojenga 2003:450-474 in Schroeder, 2008:11).), Zambian languages have an inventory of five vowel phonemes corresponding perfectly to the five vowel graphemes in the Roman alphabet 'a e i o u'. In all the languages $\boldsymbol{i}$ is a front close vowel, $\boldsymbol{e}$ front mid, $\boldsymbol{a}$ central open, $\boldsymbol{o}$ is back mid and $\boldsymbol{u}$ is a back close vowel.

The five vowels in Zambian languages are also consistently the same in all the words. This is not to say that they are not affected by phonological processes that can alter them in the languages such as vowel harmony and coalescence. What is important is that these processes do not introduce new vowels beyond the five. Changes that occur are mainly to do with vowel length and these are reflected in the orthography. For example, vowels can fuse at morpheme boundaries as between prefixes and stems such as between the prefix for nominal (noun) class $2 a b a$ - and the stem -ana 'child' which becomes abaana 'children'. This results in vowel lengthening. We can also have fusion or coalescence that results in creating a new vowel different from those fusing as in ka+imba which becomes keemba 'it sings' (Kikaonde) or 'singer' (Bemba). Apart from these changes in nouns we also have the feature of vowel harmony especially in verbal extensions. This is where the vowel in the suffix extension changes to correspond in at least one phonological feature to the one in the verb root. For example, the derivational applicative verbal extension in Bantu languages is -il-, but it is realised differently in the two Bemba words below:

$\begin{array}{llll}\text { 1. } & \text { a. } & \text { bik-a 'keep' } & \text { bik-il-a 'keep for' } \\ \text { b. } & \text { Bomb-a 'work' } & \text { bomb-el-a 'work for' }\end{array}$

As can be seen, because of the presence of the mid back vowel /o/ in the root in 1(b), the high front vowel $/ \mathrm{i} /$ in the extension, has to harmonise to the vowel height of /o/ and become a mid-front /e/. Since the spelling represents what is heard, even if learners didn't know how vowel harmony worked, their reading and spelling could not be affected. This extension like others, is not represented as invariant in the Zambian languages orthographies. However, there has been some controversy as to what to do with vowel fusion across word boundaries as in the example below:

2.
a. umuntu
na
imbwa
a person
and
a dog
b. umuntu
ne
embwa
a person
and
a dog

Although what is heard in rapid speech is represented in 2(b) neembwa (a single word) where the coordinator na 'and' is joined to the following noun 'imbwa', there is need to preserve lexical integrity, that is, to show boundaries between words in writing. The recommendation in the orthographies seems to allow this fusion. As a matter of fact, fluent readers pronounce 2 (a) as in 2(b) 
(See Cahill and Karan, 2008 for a discussion of related matters).

Vowel length is distinctive in Zambian Languages, that is, it affects meaning as shown in the two Nyanja words in (3) below:
3.
a. Mbale 'plate'
b. mbaale 'brother'

The two words have different meanings although the vowels sound the same apart from one having longer duration. In all the Zambian languages except Luvale, in which vowel length is believed not to be semantically contrastive, the orthographies reflect vowel length distinctions through the doubling of the vowel grapheme as shown above in (3) (MOE, 1977). This is not, however, strictly observed by writers in some Zambian languages who leave it to context to disambiguate the intended meaning. This is not a good state of affairs. Some writers do this out of ignorance perhaps because these aspects were not properly taught to them in school. In some cases, some missionaries who reduced most of our languages to writing did not reflect vowel length in their orthographies or used diacritics (like bars above the vowel, $\overline{\mathbf{o}}$ ) that writers find cumbersome to include.

Beginning readers, in particular, need to be sensitised to vowel length distinctions very early and, as they develop as readers, they should be helped to understand the morpho-phonological processes that are responsible for changes in vowel length. There is need, therefore, to emphasise aspects like these in the pre-service training of teachers so that they are empowered to correctly teach the spelling of words which contrast due to vowel length. It is gratifying to note that the new literacy programme called the Primary Literacy Programme (2013) has explicitly included the teaching of the distinction between short and long vowels from the beginning.

There are no diphthongs or reduced vowels such as the English Schwa /ə/ as in the first letter of apart, in Zambian languages. Vowels are syllabic in Bantu, so two different consecutive vowels belong to different syllables e.g. eisa 'he/she shouldn't come'. In English two different consecutive vowel graphemes are always interpreted as diphthong digraphs (where the tongue glides from one vowel position to another rapidly) as in the word fear /fior/.

The English vowel system is one of the most complex and inconsistent in the alphabetic writing system. The five vowel graphemes in the alphabet and ' $\mathbf{y}$ ', which in some words is vocalic as in 'try', are used to represent some 15 vowel phonemes in American English (Akamajian et al, 2010:87) or 20 in British English if we include both monophthongs (single vowels) and diphthongs (Tomlinson and Ellis, 1990:99). This means that there is no one-to one correspondence between the phonemes and graphemes used to represent them. For example, the grapheme ' $u$ ' in these words clearly represents different phonemes: cup, put, use and lurch. This inconsistence is also seen in the doubling of vowel graphemes, for example, in foot /fot/ there is a mismatch between the grapheme and phoneme and also the double letters don't represent vowel lengthening. In poor, the 'oo' actually represent a diphthong /ひə/. Moreover, English also has some words with split diphthongs such as cake /keik/, take /teik/ and so on. It is clear why such words are better learnt as whole visual patterns because their spelling cannot be determined from their pronunciation. The above mismatches are not found in Zambian and Bantu languages in general.

\subsection{Consonants}

There are differences in the way consonant inventories are worked out in Zambian languages; this depends on whether consonant clusters are included in addition to digraphs. Digraphs are two letter graphemes representing one phoneme while consonant clusters generally are blends of consonants which can be sounded out separately while the letters in a digraph cannot. Digraphs include 'sh' as in the English ship, or 'ch' as in church. Some digraphs in Zambian languages like 'ph' in Nyanja and Luvale represent the phoneme /p/ uttered with aspiration (said strongly with a puff of air). The inventories of consonant phonemes vary between 28-30 if we only count single consonants and digraphs. In all the seven Zambian languages used in education the letters ' $x$ ' and ' $q$ ' are not found. Some letters which are also not found in some of the languages are ' $v$ ', ' $r$ ' and ' $z$ ' these often being replaced by the related ' $\mathrm{f}$ ', ' 1 ' and ' $\mathrm{s}$ ' respectively, especially in loan words from English. Additional graphemes used include digraphs such as sh, ch, dz, ny, ng, zh, th, ts, pf and ng' ( $\boldsymbol{\eta})$. In Tonga, additional graphemes are used to indicate, for example, differences between plosives and fricative allophones such as bb as a voiced bilabial plosive and a single $\mathbf{b}$ indicates a voiced bilabial fricative sound. In Nyanja (or Chichewa) the voiced bilabial fricative has been represented as $\hat{\mathbf{w}}$. Another 
phoneme that is represented with a variety of graphemes in the languages is the velar nasal which is represented as $\boldsymbol{\eta}$, ng' and $\tilde{\mathbf{n}}$. There is certainly need for orthographies to be harmonised to make it easy for readers of other languages to read.

Most of the consonant clusters found in the Zambian languages are what are called pre-nasalised consonant clusters because they are preceded by a nasal or homorganic nasal (a nasal that shares the place of articulation with the following consonant especially in word initial positions) although there are also other types shown in Table 1 below:

Table1. Some common consonant clusters in Zambian languages

\begin{tabular}{|l|l|}
\hline Type & Word Examples \\
\hline Nasal + Stop/Fricative/ semi-vowel: nd, nt, mf, my & penda 'count' (Nyanja) mwenyi 'visitor' (siLozi) \\
\hline Nasal +Stop/Fricative +Semivowel: mbw, mfw, nky, & sendwe 'craftsman' (Kaonde), nyumba 'house' (Nyanja) \\
\hline Stop/fricative + semivowel: pw, fw, by, bw, vy, kw & kwindi 'rat' (Bemba), \\
\hline Approximant + semi-vowel e.g. ly & lya 'eat' (Bemba) \\
\hline $\begin{array}{l}\text { Some of the above types + aspiration (represented by } \\
\text { 'h'): in Nyanja: mphw }\end{array}$ & \\
\hline
\end{tabular}

While digraphs might not be predictable in terms of pronunciation such as 'ch' (this represents the palatal affricate/ $\mathrm{g} /$ ) clusters like the pre-nasalised consonants in Table 1 are. For example, a learner who can sound out ' $d$ ' and ' $n$ ' can blend 'nd'. Some consonant clusters are due to phonological processes such as semi-vocalisation; for example, 'ky' is a result of semi-vocalisation when the high front vowel /i/ for example in a prefix comes before any other vowel in the noun stem as happens in in $k i-a m b a$ which becomes kyaamba 'it says' (Kaonde). The same happens with ku- coming before /a e i/ which becomes ' $\mathrm{kw}$ ' as in uku —amba ukwamba 'to start' (Bemba). Although the resulting form makes it difficult to tell what the original prefix is in such words, the orthography does not retain the original prefix. Children learn these forms as part of syllable patterns e.g. /kwa, kwe, kwi, kwo / because this is what is heard. In terms of spelling, some research findings in Bantu languages such as Swahili (Alcock and Ngorosho, 2003, 2007) and Nyanja (Kaani and Joshi, 2013) report that children have difficulties spelling words with consonant clusters. In the case of Zambia this might be due to poor instruction in which children do not learn such clusters as part of syllable patterns.

\subsection{English Consonants}

One major difference between Zambian languages and English orthographic representations of consonant phonemes is that in English there is overrepresentation of phonemes by graphemes (cf Cahill and Karan, 2008:8). English has 24 consonants (Akamajian et al, 2010:87) which in many cases do not correspond to single phonemes in the language. For example, some phonemes such as /f/ are represented in English words with multiple graphemes such as 'ph' in phone, ' $\mathrm{f}$ ' in find and 'ough' in enough. Note, however, that 'ough' represents different phonemes in thought and thorough, etc. The overrepresentation is also seen in unnecessary letter doubling e.g. in 'effect', 'well' and so on. Moreover, some letters are no longer pronounced in words such as the ' $\mathrm{k}$ ' and 'gh' in knight/nait/. It is worth pointing out that there are some cases where there is a direct one-to one correspondence between graphemes and phonemes in English (especially in short words like big, send, etc.) but not up to the levels found in Zambian languages.

English has many more digraphs and trigraphs than Zambian languages. Just to give a few examples that show how inconsistent the spelling system of English is, the digraph 'ch' representing the phoneme / $\mathrm{t} /$ in words like church, also appears as part of a trigraph in 'catch', but not in 'rich'. The consonant clusters in English can be found in both initial and final syllable positions as discussed below. In Zambian languages they are only in syllable initial positions. Theoretically we would expect spelling in English to be even more difficult than in Zambian languages although this might be affected by the strategy used in learning to recognise words (but see Kaani and Joshi, 2013 for a different view).

\subsection{Syllables}

Syllables are considered to be hierarchical rather than just a string of linear phonemes (see Fowler, Treiman and Gross, 1993). They are composed of an onset and rime (rhyme). The onset is a consonant or consonant cluster preceding a vowel while the rime is the vowel (also called the peak) and the following consonant(s). For example, in the English syllable street, the onset is the cluster 'str' while 
the rime is 'eet'. The rime is further segmented into a nucleus (the vowel) and the coda, the consonants after the vowel. Syllables that have no codas are called open syllables while those with codas are closed. Open syllables are said to be simpler than closed ones. Zambian language syllables are all open and simple basically in spite of some occurring with clusters in their onsets. There are four possible syllable types shown below with Bemba examples:

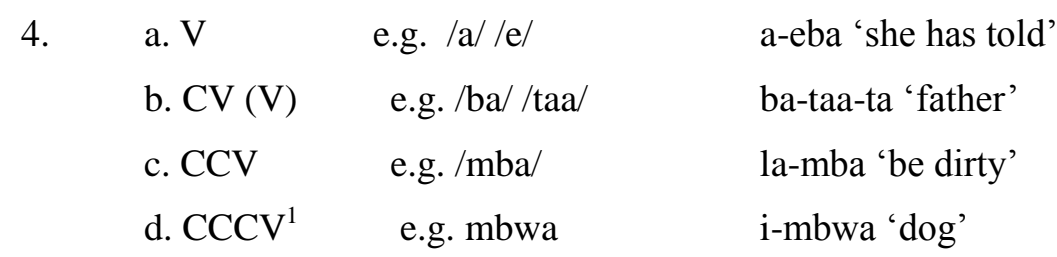

This open nature of the syllables in (4) makes it easy to tell where syllabic boundaries are in words e.g. ba-lee-pya-nga 'they are sweeping'. English, on the other hand, has more complex syllable types said to number about 16 (Abercrombie, 1967). There are 31 different types of cluster onsets in English (Anthony and Francis, 2005). The majority of English syllables end with codas and hence are closed: these types are found CV VC, CVC, CCVC. Frost (2005: 274) estimates that given the 24 consonants and 15 vowels in English, the number of possible syllables in the language would be 15,000. If English was using a syllabic writing system, this would mean that there would be 15,000 unique symbols to remember! Compare this to the Japanese Kana syllabary which has only about 116 symbols for the syllables in the language. Japanese has 5 vowels like Zambian languages, 14 consonants and open vowel types $\mathrm{V}$ and $\mathrm{CV}$. From this we can tell that Zambian languages could also have been easily written in a syllabary which could have had, of course, slightly more symbols than Japanese, perhaps a couple more hundreds, but certainly far fewer than those in English. The point here is that English has a complex syllabic system in which syllable boundaries are sometimes difficult to define (Frost, 2005). It is thus easier to teach reading using a syllabic approach in Zambian languages than in English.

\subsection{Tone}

Tone is contrastive in Zambian languages. Some otherwise identical words can differ semantically because of tone. However, it is not indicated in any of the orthographies of the seven Zambian languages used in education mainly because it was felt that diacritic marks used to indicate tone would have made reading of the languages more difficult.

\subsection{Morphology}

Bantu languages are classified typologically as agglutinating languages which means that words consists of strings of morphemes expressing semantic and grammatical information, literally glued together. These morphemes can be inflectional or derivational affixes and roots or stems. Verbs in particular can be full sentences/clauses and can contain up to 11 inflectional or derivational affixes in addition to the root although not at the same time (Nurse, 2008). English is largely an isolating language although it has Latin and Greek words that have inflectional and derivational affixes, the core Anglo-Saxon vocabulary is largely of an isolating nature. We can see this isolating tendency in English in the examples below:

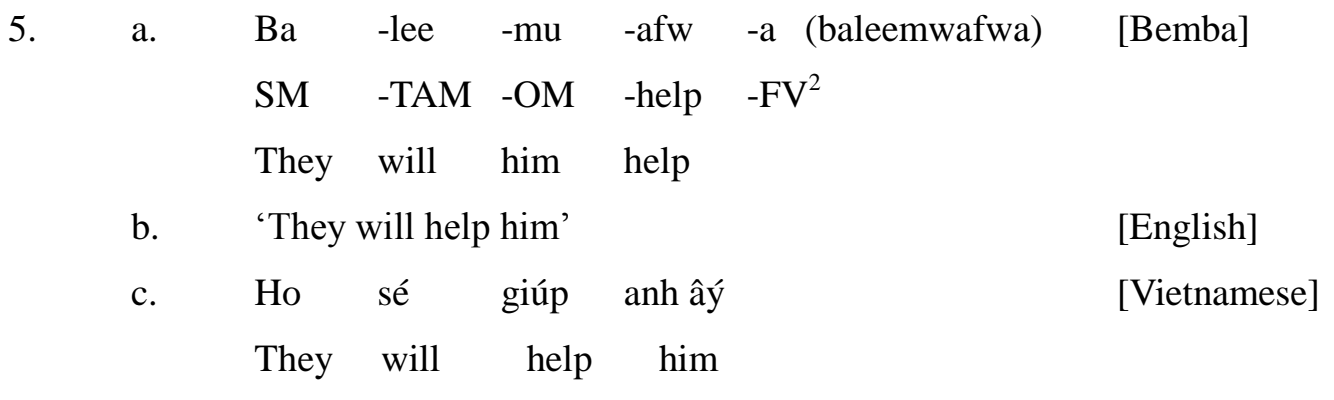

\footnotetext{
${ }^{1}$ The pattern $\mathrm{CCCCV}$ which some people may claim exists is simply the CCCV with aspiration indicated by ' $\mathrm{h}$ ' as in this Nyanja syllable mphwa as in mphwawi 'laziness'. (Banda, PC)

${ }^{2}$ The symbols used here are SM (Subject Marker), TAM (Tense Aspect Marker), OM (Object Marker) and FV (Final Vowel).
} 
The sentence in (c) is in Vietnamese which is often cited as the quintessential isolating language. The additional morpheme in the Vietnamese example (âý) is an indicator of the third person singular (Trin, $\mathrm{PC})$.

It is important to note that in the Bemba example above, the subject marker $b a$ 'they', tense aspect marker lee 'will', object marker, $m u$ 'him/her' and the final vowel are all syllables. This is also the case with locatives, negation markers and in nouns, prefixes. Thus in many cases, syllables coincide with grammatical morpheme boundaries. The syllable is, therefore, a salient phonological unit in Bantu languages in general. It is important to note that all Zambian languages except Lozi, are written conjunctively, that is, morphemes are linked up into words. In Lozi there are some disjunctive tendencies, a legacy of the orthography developed by Protestant Paris Missionary Society (Kashoki, 1978) who may have based the orthography on French.

The examples in (6) below are the basic verb root forms in most Zambian languages; these ones come from Lunda (Kawasha, 2003:155-156):

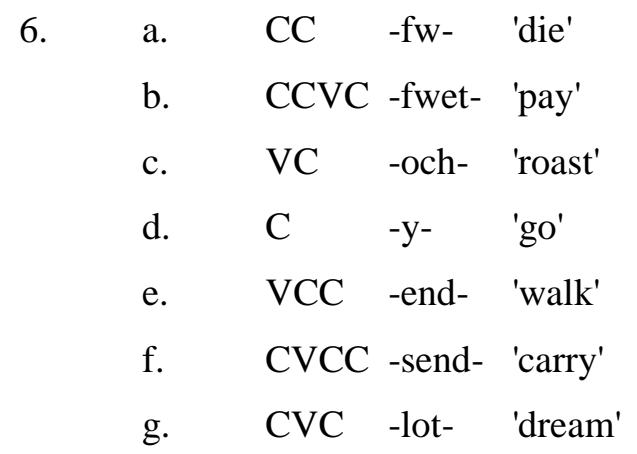

Although these roots end in consonants, the addition of the verb ending or final vowel recovers the regular CV syllabic structure of Bantu languages as in -fwa "die" in 6(a).

\section{READING INSTRUCTION}

In this part of the paper, I consider implications of the above phonological, morphological and orthographic facts for the teaching of initial literacy in Zambian languages compared to English. This will also lead to a critique of methods used in the past and currently in teaching initial literacy and why they may have been or not been effective. I highlight areas of research to inform the effective teaching of literacy in Zambian languages. I do this by considering four of the five component skills or processes that have been identified as important in the teaching of reading (see NRP, 2000). These are phonological awareness, phonics, fluency and vocabulary. Lack of space has made it difficult to include comprehension.

\subsection{Phonological Awareness}

As we have already remarked, writing systems are based on some units of the spoken word: syllable, phonemes or morphemes. In the alphabetic writing system in particular, it is the phonemes which are represented by letters or graphemes. The implication of this for learning to read is that children must discover these phonemes in their languages and then associate them with graphemes used to represent them in writing. Phonological awareness refers to the 'ability to recognize, discriminate, and manipulate the sounds in one's language, regardless of the size of the word unit that is the focus' (Anthony and Francis, 2005:2; cf Treiman, 1987). Researchers also include intermediate sub-syllabic units like onsets and rimes. Phonological awareness is said to have moderate and statistically significant effects on reading and spelling and that children whether normal or those with reading difficulties benefit from direct instruction in phonological awareness (National Reading Panel, 2000). Instruction can involve tasks like tapping to syllables, phoneme deleting, isolating, and substituting, segmenting, identifying rhymes and so on. It is important to realise that phonological awareness has to be linked directly to letter sound identification otherwise it becomes a meaningless exercise (see McGuinness (2004) for a fuller discussion). Moreover, the unit of sound focused upon such as the rhyme, phoneme, syllable or word, must be in some way a relevant unit in helping learners decipher words in the target language. 
There are language specific differences that can influence the rate of development of phonological awareness, for example, the saliency of a particular sound unit in the language. For example, children whose languages have simpler syllable structures develop syllable awareness earlier than children acquiring languages with more complex syllables. This has been found in Turkish (Durgunoglu and Oney, 1999) which is also an agglutinating language like Bantu languages but also in Spanish (Carreiras, Alvarez and de Vega 1993) and Italian (Cossu, Shankweiler, Liberman, Katz and Tola 1988). English and French children don't develop syllable awareness as early as those in the above languages apparently because of the complex syllable structures in these languages. English children instead are said to be more sensitive to rhymes (Bruck and Treiman, 1992; Bruck, Genesee \& Caravolas, 1997 cf Nation and Hulme, 1997) because these are read to them or they learn to recite them early before they come to school.

The development of phonemic awareness, the ability to isolate and manipulate phonemes is said to arise when literacy instruction starts. There is a reciprocal causation process between learning to read and phonemic awareness (Stahl and Murray, 1994; Stanovich, 1981). But even here, early phonemic awareness as a predictor of early reading achievement depends on the language and its orthography. It has been found not to be a major predictor in transparent orthographies like Turkish, Finnish, and Italian but is significant in English (Clinton, Quiñones, and Christo, 2011). Reasons given include the fact that children in transparent orthographies have less problems working out connections between sounds and letters which is not the case with English.

It should be obvious from the linguistic information provided above that the choice of the sound unit(s) (whether phoneme, rime or syllable) used to teach phonological awareness should be the one that is used in decoding print in the language. Children learning to read in Zambian languages can obviously benefit from phonemic awareness and syllable awareness but not rime awareness as we discuss below. We have seen that syllables, in particular, are simple and easily identified. It can also be claimed, although this needs further research, that syllables are very salient to children in Zambian languages. For example I overhead a four-year-old girl telling her brother in what she thought was a secret code: nde-i-sa-ku-se-be-le-la 'I will come and inform on you' which clearly showed that she knew syllabic segmentation in her language (Bemba). Slightly older children also play word games like saying syllables in words backwards such as la-nda 'speak' becomes 'nda-la'. We need research in language games that could be exploited for teaching phonological awareness.

The clear grapheme-phoneme correspondence in Zambian languages also means that we need to heighten children's awareness of phonemes and hence phoneme awareness tasks are important. They are important too because of the fact that children are expected to transfer reading skills to English and a focus on this unit can help them to decode English words later. A good start has been made in the new literacy programme where each letter sound is introduced through a phonemic identification task. Children are asked to identify initial sounds of words uttered by the teacher, which is one simple phonemic awareness task that is effective in facilitating acquisition of phoneme-grapheme correspondences in early stages of learning to read (McGuinness, 2004:173).

The use of rimes (or rhymes) in Zambian languages is of doubtful value. In English, rhymes are used as a way of preparing learners to use analogy to identify words later in reading because rime similarities are common in the language. For example, a child can compare mentally the rime -at in cat, to read ch-at, f-at, r-at, m-at and so on. It is difficult to imagine how useful this method would be in identifying polysyllabic verb structures in Zambian languages which don't remain as stable words because they are modified by additions of different affixes. Rhyming is quite foreign to the average Zambian child because rhymes do not feature in children's games or even songs, not even in lullabies. For example, in the Bemba lullaby below (7), there are no end rhymes (The translation is literal). There are other devises used instead.

(Mwansa, forthcoming):

7.

$\begin{array}{ll}\text { Umwana alila } & \text { A child cries } \\ \text { ati bampaape } & \text { that they carry me on the back } \\ \text { mupapa yandi } & \text { in my carrying cloth } \\ \text { yaluka taata. } & \text { weaved by my father }\end{array}$



Taatanshi?
whose father?
Taata ShiMwenya.
the father of Mwenya.

Words such as bampaape 'they carry me on the back' and mupapa 'carrying cloth' are related as verb and noun versions of the same root. This word play is quite common in some languages. The other technique is word repetition; note, for example, that taata 'father' is repeated three times. We can also see that most of the lines have roughly five syllables each except for the first and fifth lines. The beat is very regular. In English many strategies have been used to teach children to read because of the problems inherent in its orthography; but these problems dn't exst in Zambian languages. Research in South Africa compared English and Zulu Bantu children's reading of pseudo words containing rimes frequently found in written English. English children performed better than Zulu children which was interpreted as showing that rimes may not be salient units for the Zulu children learning to read in Zulu (Greenop, 2004 in De Sousa and Broom, 2011:4) and even those learning English as a second language performed poorly on a rime task (De Sousa and Broom, 2011:10). In Zulu, as in Zambian languages, syllables are more salient and Zulu has a transparent orthography.

One feature that can be exploited in teaching phoneme awareness in Zambian languages is the natural alliteration that is created by the use of obligatory agreement prefixes between nouns, adjectives, demonstratives and verbs. An example is give below:

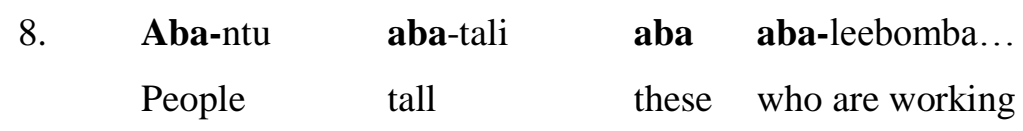

'These tall people who are working...'

Note the repetition of the agreement prefixes 'aba'.

\subsection{Phonics or Whole Words?}

The so-called reading wars in English are due to the complexities found in the orthography (Adams, 1990; Chall, 1967). The war has been basically about whether to teach initial literacy using phonics or whole words or texts. As we have seen from the discussion of the English orthography above, there are good reasons for supporting both sides and in fact some have advocated for a balanced approach which incorporates elements of both. While it is easy to read by grapheme-phoneme decoding some regularly spelled CVC words like dog, this method fails when it comes to irregular ones like thought. English spelling in many cases has preserved the morphology of words (especially borrowed ones) at the expense of phonology. To read irregularly spelled words, methods of teaching such as using rhyme analogies mentioned above or by rote learning of the whole word can be used although there is an upper limit of some 2000 words that can be learnt in this way by an average person (McGuinness, 2004, see also Ziegler and Goswami, 2005). Much scientific research, however, seems to give support to the use of synthetic phonics in teaching initial literacy in English (see the NRP 2000; Rose, 2006). But this reading war is and has never really been ours in Bantu languages. We have sometimes accepted wrong advice because it has always been linked to funding. However, we seem to have funded failure most of the time.

Methods such as memorising whole words as sight words, or using rhymes to decipher other words are not very useful for Bantu languages because of the latter's agglutinative nature. Words in Bantu languages rarely have fixed stable forms. For example, even nouns such as taata 'father' can mutate by taking different prefixes and have different shades of meaning as shown below:

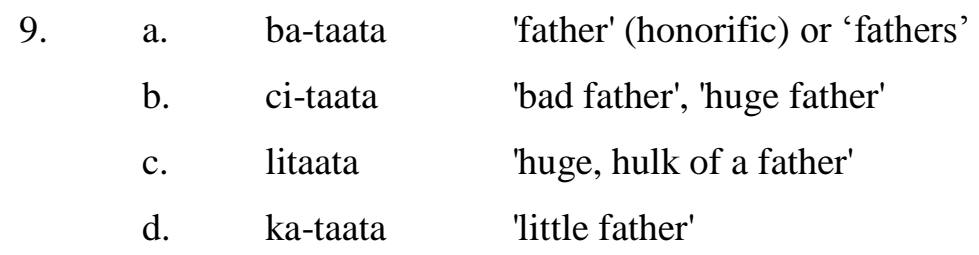

It is difficult to imagine how all these forms could be stored in memory as full sight words. Verbs as we have seen earlier on are even more complicated. It is very likely that these Bantu words are stored in the mental lexicon in a decomposed form, that is, separately as morphemes: stems, roots, and 
affixes. This is supported by the following facts: the word forming processes are very regular and the morphological processes are very productive; the morphemes have transparent meanings and clear boundaries between them (see Allen and Badecker, 1999, for a discussion of related ideas.) What is likely to be remembered as sight forms in Zambian languages are syllables, some of which constitute grammatical morphemes. We need further research to confirm this. We also need research to ascertain what is stored as a word (especially in relation to the verb) in the mental lexicon of Bantu speakers.

From this discussion one implication for teaching reading would be to help learners focus on learning syllables to the point of making them sight forms. This might be more beneficial than trying to use whole language approaches of memorising whole words because this is very difficult in Bantu languages.

The fact that Zambian languages have transparent orthographies that facilitate rapid acquisition of literacy has been known for a long time. Missionaries who devised the original orthographies for most of our languages understood this very well. For example as early as 1929 it was stated in the syllabus for teachers at Rosa Catholic Mission in Northern Zambia that since there was a direct correspondence between letters and sounds in Bemba, there was no need to teach in the initial stage names of the letters. Obviously, these missionaries saw no reason why a beginner should be burdened with two pieces of information like: this is the letter 'ei' which makes the sound /a/. Why not just say this letter makes the sound /a/? Missionaries used phonics especially at the syllabic level to teach local languages and this worked very well. Learners were able to read within the first year and even write letters in the second year of primary school.

It is true that phonics can be boring if taught in a banking fashion: that is, going through a list of graphemes without children seeing how this works in words and sentences they can read. Children need to feel a sense of achievement. Motivation is an important ingredient in learning to read and one effective way children get motivated to read is to listen to stories read to them and also the children doing the reading themselves.

But phonics need not be boring. The current Primary Literacy Programme (MESVTEE, 2013), for example, is designed to make children read a few decodable words every time they learn a new consonant phoneme and can make syllables with it. The sequence in teaching proceeds from phoneme identification, for example, children are asked to tell what sound they hear at the beginning of bataata 'father', /b/. Then they see this in writing, both in small and capital letters. They practice writing it after which they form syllables with it (including those with long vowel sounds): ba, be, bi, bo, bu, baa, bee, etc.. Then they form short words with these syllables (examples in Bemba): baba 'itch', beebe 'tell them', bobe 'they are yours' etc. Although this is not stressed in the programme, children should also be encouraged to play with combinations that are not words in the language. Reading nonwords is a good sign of decoding ability and a good sign too of the fact that they can transfer their decoding skills. What needs urgent attention in the current programme is the supply of reading materials to reinforce the incipient reading skill.

The New Breakthrough to Literacy (NBTL) programme that has been replaced in Zambian languages was a truly eclectic one. It had some elements of analytic phonics, Language Experience Approach with a twist, and Whole Language aspects. The phonics part involved teaching a phoneme each day, which was introduced by using a printed word beginning with that phoneme. The disadvantage of this is that children see letters in the word that they have not yet learnt.

In the Language Experience Approach component, conversation posters, which were pictures based on four themes of the home, the school, the town and the farm were used to solicit key sentences for lessons (Sampa, 2005). Learners were asked to make a sentence about one of the pictures and if this corresponded to the key sentence, the teacher showed learners how to write it and them to read it with her. The sentence could later be decomposed into phonemes and syllables and pupils would construct the sentence with letter or syllable cards on a sentence maker. As can be seen here, this was basically repeating part of what was being taught in the phonics component. It was not very clear whether there was a link in content and sequencing of materials between the phonics part and the Language Experience Approach part. In view of the fact that Zambian languages have very transparent orthographies, it is difficult to understand why such desperate measures were taken of teaching word reading in two different ways often in the same hour. It was not only an overload for learners but also taxing for the teacher. As a matter of fact teachers did complain about the amount of work involved. 
In addition, the idea of using themes and key sentences did not exhaust all possible phonemes or even syllable types that are found in the languages. Perhaps it was expected that learners would use analogy to read unknown words. In European contexts, these methods tend to benefit children from high income homes who also have reading support at home: parents read to them and they are exposed to a lot of children's literature which is not the case in Zambia. This is also the case with the Whole Language method where it is argued that learning to read is as natural as learning to speak and that you learn to read by reading. The Whole Language part involved daily reading from short story books. The teacher was expected to read to the learners at the beginning of each literacy hour as a way of motivating them to read and also showing them how to read fluently. Learners were also encouraged to visit the reading corner, a small library in class to read books they wanted. All the story books used were translated from English perhaps to have uniformity across the languages. These were not decodable stories and were unrelated to what was being taught in phonics.

The NBTL programme was said to be very effective in early evaluation reports (Sampa, 2005,). Learners were said to be reading at two or more grade levels above their level. But it was initially supported by British Overseas Development funds and when the support ended, the expensive materials required could not be procured. There was also a sort of Hawthorne effect on these results initially achieved. The teachers who had undergone training had benefited from financial incentives (through workshop attendances, for example) and were highly motivated. Needless to say, they taught well. But those who were trained as part of school in-service programmes later did not have the same levels of motivation. Soon the programme was not being followed faithfully and in fact was being abandoned in some cases because teachers found it very involving, what with all the components it had.

One other serious shortcoming of the NBTL programme implementation in Zambia was the short transition time to English literacy, which was just after a year. Apparently, the main objective of using local languages was to facilitate English language literacy acquisition later. In many cases, once English literacy was introduced, literacy in the local language was largely abandoned. There is nowhere in the world where children become fluent readers in just one year. For most, fluency will come after 3 years and in the fourth, children can transition from learning to read to reading to learn. It was not surprising, therefore, that in later grades, many learners appeared to regress; they became poor readers. For example, I tested some 136 grade 3 and 4 learners from five primary schools in Lusaka in 2007 who had gone through the NBTL programme. I used common Nyanja words drawn from school story books a grade below theirs. The result was that only $36 \%$ were able to correctly decode the words. My conclusion was that this was akin to semilingualism, the situation of not being able to develop proficiency in both the first language and second language because of poor exposure or teaching. The transition to English appeared to arrest the development of literacy in the Zambian language. National assessments at Grade five done since 1999 have shown that literacy levels have stagnated below 40\% (MESVTEE, 2013). The South African Consortium for Monitoring Education Quality (SACMEQ III) of 2010 noted that among Grade 6 learners that were tested in reading, only $28.6 \%$ were able to read at a basic competency level.

In the current literacy programme, the period for teaching initial literacy in local languages has at least been extended by another year and transition to English literacy is in the third grade. Another good thing is that the exposure to literacy in Zambian languages is greater because content subjects are being taught in local languages up to grade four.

Other areas that need to be researched in relation to the implementation of the new literacy programme include the teachers' competence in teaching a synthetic phonics programme based on phonemes. My observations are that some teachers have very poor backgrounds in phonetics and phonology of Bantu languages since these are not practically taught in most colleges of education. They are likely to have difficulties articulating sounds and might misled learners by teaching letter names rather than sounds. I suspect many would be more comfortable with syllables and might be using syllables to teach phonics. We also need to look at what types of reading strategies children are using to recognise words in local languages: is it letter by letter decoding or the use of syllables or larger units? There is also some growing realisation that spelling might be harder than reading (Alcok and Mborosho, 2003; Kaani and Joshi, 2013). This needs further research to collaborate these findings and to determine whether this might be due to the teaching method. 


\subsection{Fluency}

Fluency has been defined as "the ability to read a text quickly, accurately, and with proper expression" (NRP, 2000:3-5). Speed in reading is achieved by very rapid or automatic decoding of print, and reading with expression requires that a reader observes the punctuation in a text, that is, read in meaningful chunks and also paying attention to intonation. Thus fluent reading is a preliminary step of reading comprehension because it helps organise the text in a meaningful way. In addition, automatic and accurate decoding helps to free up working memory to attend to constructing the meaning of a text. It is, therefore, not surprising that there is a moderate correlation between fluency and reading comprehension (NRP, 2000). Abadzi (2006 and references therein) argues that fluency develops by repeated reading of a word, for example, until a pathway is activated in the mind. An exact neural model of the word is formed which reflects its spelling, pronunciation and meaning in long term memory. Then this word can be retrieved in less than 150 milliseconds when it is seen in a text. Abadzi (ibid) further argues that working (or short term) memory can only keep 7 items for about 12 seconds. This means that to understand a sentence one has to decode it within this time limit otherwise some of the information can be forgotten. This is an important point to bear in mind when constructing sentences for children's reading texts; they need to be short. Children must read at least between 45-60 words per minute to understand a text (Abadzi, 2006:36).

Much of this research has obviously been done in English. This means that there might be limitations in applying it to Bantu languages. Some of these constraints are to do with the nature of words in English compared to Bantu languages: how many Bantu words can working memory retain? Or what does the reading speed of 45-60 words per minute translate into in a Bantu language? In fact, in thinking about reading speed it might help if we knew the rate of speaking in ordinary conversational speech. In English it has been estimated at 250-300 words per minute (McGuinness, 2004 and references therein). What would this be in a Zambian language and would that be closer to the fastest reading speed of a university graduate as is in English? We need such baseline data to start working out the optimum speed for reading in a Bantu language. In addition, we need to explore this connection between fluency and reading comprehension: is it the case that slow accurate decoders are poor readers in Bantu languages. In Bantu languages children can learn to read within a short period of under a year because of the transparent orthographies but how good is their comprehension?

I mentioned above that the NBTL programme was ineffective in developing reading fluency in Zambian languages because the transition to English was too abrupt, just after a year. However, it is also worth pointing out that the types of reading materials provided and the techniques of teaching did not support the development of fluency in reading. Much of the research of fluency training indicates that children need to recycle vocabulary, they should see the same words many time in order to store full copies of them in their long term memory. In the case of Zambian languages, perhaps they need to store syllabic patterns or some morphemes. They need to read decodable texts though. These are texts with syllables or words that they have already met. There is certainly need for research in this ara.

\subsection{Vocabulary}

One major difference between Zambian languages and English is that the latter has a long literary tradition that influences the spoken language. Differences are noticeable in the speech of the welleducated, middle and upper income English people and the less educated lower income ones in terms of vocabulary size and even grammar, favouring the educated. These differences are passed on to their children so that at the time the two sets of children start school, they bring different levels of vocabulary and language use to school (Pearson and Cervetti, 2013:513).

In the Zambian context, educated parents are not necessarily expected to speak the local language in better ways than the uneducated. Their speech might be full of code switching between English and the local language. Rural parents may be more conservative in their speech by using less code switching. We need to research these differences in terms of vocabulary size and quality of language to which children are exposed to have accurate information that can profitably be used in developing appropriate reading materials for all categories of children. Dialectal differences in the language of the rural and urban areas also need to be researched to ensure that they don't disadvantage any group.

In general, the initial literacy stage in Zambian languages does not present major vocabulary challenges to our children unless a child is learning in a second language because most of the words 
used are very simple and common. Once children learn to decode, they are able to understand the words they are reading because they are already part of their spoken vocabulary. This is the beauty of learning in a mother tongue or familiar language. But in later stages of education vocabulary instruction is necessary. Here too we need to think about how instruction can best be conducted in poorly resourced contexts like Zambia's-where learners don't have much literature in their languages.

\subsection{Social-Economic Context}

Parental social and economic status is said to play a big part in children's literacy development and success in high income European countries. Children from higher income homes are exposed to reading early in life; they do not only observe their parents and siblings engaged in literate activities but are also directly read to. The homes and local areas are replete with environmental print; advertising, labels on food stuffs, and so on. These children thus pick up ideas about the uses of print an even how one reads. The transition to school for such children is made easier because sometimes they start formal education already able to read. Poor ones, of course, have less exposure to literature and parents might not support early literacy.

The situation in Zambia is rather complicated. Many children do not have the luxury of owning books especially those in local languages (cf Musonda and Kaba, 2010). This is partly an economic problem but also a cultural one. It is true that some families in urban areas and more so in rural areas cannot afford even three meals a day; one wouldn't expect them to spare a coin for a book. But there are also quite well-to- do parents with some education who have never stepped into a bookshop in their lives. They have no reading culture which simply means they never developed an interest in reading because reading was strenuous, a chore that had to be done and forgotten. The last novel they read was at secondary school in literature and perhaps they never read it but read notes and commentaries on it. Many people never develop fluency in reading in a second language and even after college perhaps read at the rate of a grade 5 native English learner. There is also the problem of availability of suitable books to read. It is not surprising given the above, that there are very few parents who buy books for their children, even fewer who have the time and interest to read to their children.

When it comes to environmental print, we have two issues. What children see in the environment is largely in English. Most billboards are in English; foodstuffs are labelled in English, etc. Those in rural areas don't see much of the above environmental print at all. What children bring to school is a wealth of tacit knowledge of their language's phonology, morphology and syntax and these need to be connected to what is new: learning the graphic system (letters). The school has to compensate for the poor literacy background of the learner by providing reading materials that can engage and create lifelong readers. Teachers must be material writers, creating stories and texts to foster the developing literacy because reading materials might not be available. These are the issues we should be thinking about.

\section{CONCLUSiON}

In this paper I have showed that there are many differences in the linguistic features that are reflected in the orthographies of Zambian languages and English which need to be considered in teaching Zambian languages. We also need to take into consideration differences in the social-economic and cultural context in which reading instruction is conducted. I have highlighted areas where there are gaps in our understanding of the reading process in Zambian languages which requires research so that we are better positioned to deal with uniquely Zambian or Bantu related issues in our children's literacy development.

\section{REFERENCES}

[1] Abercrombie, D. (1967). Elements of general phonetics. Edinburgh: Edinburgh University Press.

[2] Abadzi, H. (2006), Efficient Reading for the Poor: Insights from the Frontier of Cognitive Neuroscience. Washington: International Bank for Reconstruction and Development/ The World Bank.

[3] Acha, J., Laka, I and Perea, M. (2010). Reading development in agglutinative languages: Evidence from beginning, Intermediate, and adult Basque readers. Journal of Experimental Child Psychology. 105 pp 359-375.

[4] Adams, M. (1990). Beginning to read. Cambridge, MA: The MIT Press.

[5] Akamajian, A., Demwers, R., Farmer, A. and Harnish, R. (2010). Linguistics: An Introduction to Language and Communication. Cambridge: MIT Press $\left(6^{\text {th }} \mathrm{ed}\right)$. 
[6] Alcock, K. J., \& Ngorosho, D. (2003). Learning to spell a regularly spelled language is not a trivial task patterns of errors in Kiswahili. Reading and Writing: An Interdisciplinary Journal, 16, 635 - 666.

[7] Alcock, K. J., \& Ngorosho, D. (2007). Learning to spell and learning phonology: The spelling of consonant clusters in Kiswahili. Reading and Writing: An Interdisciplinary Journal, 20, 643 - 670.

[8] Allen, M. and Badecker, W. (1999). Stem homograph inhibition and stem allomorphy: Representing and processing inflected forms in a multilevel lexical system. Journal of Memory and language. 41: pp105-23.

[9] Anthony, J.L. and Francis, D.J. (2005). Development of Phonological Awareness. Current Directions in Psycholinguistic Research. 14:5 pp255-259.

[10] Bruck, M., Genesee, F., and Caravolas, M. (1997). A cross-linguistic study of early literacy acquisition. In B. Blachman (Ed.), Foundations of reading acquisition and dyslexia: Implications for early intervention (pp. 145-162). Mahwah, NJ: Lawrence Erlbaum.

[11] Bruck,M. and Treiman, R. (1992). Learning to pronounce words: limitations of analogies. Reading Research Quarterly. 27 pp374-389.

[12] Cahill, M. and Karan, E. (2008). Factors in Designing Effective Orthographies for Unwritten Languages. SIL Electronic Working Papers 2008-001.

[13] Carreireas, M., Alvarez, C., \& De Vega, M. (1993). Syllable frequency and visual Word recognition in Spanish. Journal of Memory and Language, 32, 766-780.

[14] Chall, J. 1967. Learning to Read: The Great Debate. New York: McGraw-Hill.

[15] Clinton, A.,Quiñones, M. and Christo, C. (2011). Phonological awareness: Cross-linguistic comparisons with a focus on Spanish. Interamerican Journal of Psychology. Vol. 45, Num. 2, pp. 263-270.

[16] Cossu, G., Shakweiler, D., Liberman, I., Katz, L., and Tola, G. (1988).Awareness of phonological segments and reading ability in Italian children. Applied Psycholinguistics, 9, 1-16.

[17] De Sousa, D. S. and Broom, Y. (2011). Learning to read in English: comparing monolingual English and bilingual Zulu-English Grade 3 learners. South African Journal of Childhood Education. 1:1 pp.1-18

[18] Durgunoglu, A. Y. and Öney,B. (1999). A Cross-Linguistic Comparison of Phonological Awareness and Word Recognition. Reading and Writing: An Interdisciplinary Journal 11: 281-299.

[19] Fowler, C., Treiman, R. and Gross, J. (1993) The Structure of English syllables and Polysyllables. Journal of Memory and Language. 32. pp. 115-140.

[20] Frost, R. (2005). Orthographic Systems and Skilled Word Recognition Process in Reading. In Snowling, M.J. and Hulme, C. (2005). The Science of Reading: A Handbook. Oxford: Blackwell. (pp. 272295).

[21] Kaani, B. and Joshi, R.M. (2013). Effects of Orthographic Opacity on Spelling Proficiency: A CrossLinguistic Comparison of Nyanja and English Orthographies. Insights on Learning Disabilities 10:2 pp. 45-66.

[22] Kashoki, E.M. (1978). Harmonization of African Languages: Standardization of Orthography in Zambia. Experts Meeting on the transcription and harmonization of African languages. Niamey, Niger: UNESCO.

[23] Kawasha, B. (2003) Lunda Grammar: A Morphosyntactic and Semantic Analysis. PhD Dissertation: University of Oregon.

[24] McGuinness, D. (2004). Early Reading Instruction: What Science Really Tells Us About How to Teach Reading. Cambridge, Ma: MIT Press.

[25] Ministry of Education. (1977). Zambian Languages Orthography Approved by the Ministry of Education. Lusaka: NECZAM.

[26] Ministry of Education Science, Vocational Training and Early Childhood Education (2013) National Literacy Framework. Lusaka: Curriculum Development Centre (CDC).

[27] Musonda, B. and Kaba, A. (2010) The SACMEQ III project in Zambia: A study of the conditions of schooling and the quality education.

[28] http://www.sacmeq.org/downloads/sacmeqIII/WD01_SACMEQ_III_Results_Pupil_Achievement.pdf (Accessed on 13/06/2015).

[29] Nation, A., \& Hulme, C. (1997). Phonemic segmentation, not onset-rime segmentation, predicts early reading and spelling skills. Reading Research Quarterly, 32, 154-167.

[30] National Reading Panel. (2000). Teaching Children to Read: An Evidence-Based Assessment of the Scientific Research Literature on Reading and Its Implications for Reading Instruction. Washington, DC: National Institute of Child Health and Human Development. (http://www.nichd.nih.gov/publications/ nrp/report.cfm)

[31] Nurse, D. 2008. Tense and Aspect in Bantu. Oxford: Oxford University Press. 
[32] Pearson, P.D. and Cervetti, G.N. (2013). The Psychology of Reading Processes. In Reynolds, W. and Miller, G. (Eds). Educational Psychology. V..VII Handbook of Psychology (2 ${ }^{\text {nd }}$ Ed.). New York: John Wiley and Sons. Pp. 507-554.

[33] Rose, J. (2006). Independent review of the teaching of early reading: final report. Department of Education and Skills: UK

[34] Schroeder, L (2010 Bantu Orthography. Manual. SIL e-book. (Revised ed.) http://www.sil.org/resources/ archives/9241 (accessed June, 2013).

[35] Share, D. (2008). On the Anglo-centricities of Current Reading Research and Practice: The Perils of Overreliance on an "outlier” Orthography. Psychological Bulletin, 134(4), 584-615.

[36] Tomlinson, B and Ellis, R. (1990). Teaching Secondary English. Essex: Longman.

[37] Treiman, R. (1987) Levels of Phonological Awareness. Paper presented at the Annual Meeting of the American Educational Research Association (Washington, DC, April 20-24.)

[38] Sampa, F. (2005). Zambia's Primary Reading Program (PRP): Improving Access and Quality in Education in Basic Schools. Paris: ADEA

[39] Stahl, S., and Murray, B. (1994). Defining phonological awareness and its relationship to early reading. Journal of Educational Psychology, 86, 221-234.

[40] Stanovich, K. (1981). Relationships between word decoding speed, general name-retrieval ability, and reading progress as predictors of first grade academic achievement. Psychology in the Schools, 12, 4-11.

[41] Ziegler, J.C. and Goswami, U. (2005). Reading acquisition, Developmental Dyslexia, and Skilled Reading across Languages: A Psycholinguistic Grain Size Theory. Psycholinguistic Bulletin. Vol 131:1 pp. 3-29.

\section{AUTHOR'S BIOGRAPHY}

I am a lecturer in applied linguistics in the Department of Language and Social Sciences Education, School of Education at the University of Zambia. I also lecture in linguistics in the School of Humanities and Social sciences at the same university. I serve as a literacy consultant to the Ministry of Education.

Citation: Joseph M. Mwansa. "Theorectical Reflections on the Teaching of Literacy in Zambian Bantu Languages." International Journal of Humanities Social Sciences and Education (IJHSSE), vol 4, no. 10, 2017, pp. 116-129. doi:http://dx.doi.org/10.20431/2349-0381.0410015.

Copyright: (C) 2017 Authors. This is an open-access article distributed under the terms of the Creative Commons Attribution License, which permits unrestricted use, distribution, and reproduction in any medium, provided the original author and source are credited. 